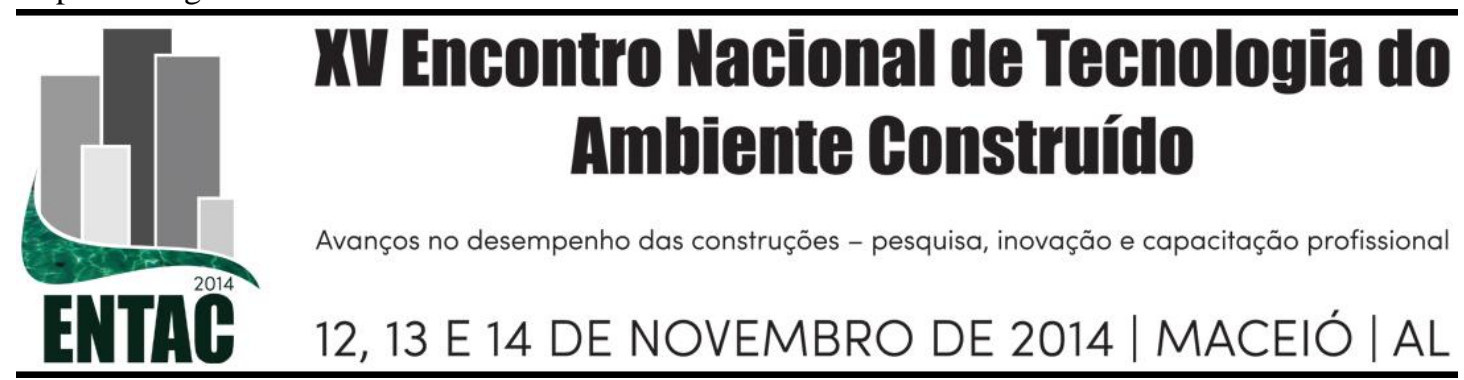

\title{
A ESTRUTURA DA EMPRESA DE PROJETO E O PROCESSO DE PROJETO DE EDIFICAÇÕES SUSTENTAVÉIS
}

\author{
DE PAULA, Nathália (1); SILVA, Vanessa G. (2); MELHADO, Silvio B. (3)
}

(1) Escola Politécnica da USP, (11) 3091-5164, e-mail: nathaliapaula@yahoo.com.br, (2) Universidade Estadual de Campinas, e-mail: vangomes@fec.unicamp.br, (3) Escola Politécnica da USP, e-mail:

silvio.melhado@usp.br

\begin{abstract}
RESUMO
A sustentabilidade ambiental de edificações tem sido uma demanda de mercado para as empresas de projeto. Assim, as empresas devem possuir uma organização interna que permita gerar um ambiente mais favorável à produção de edificações sustentáveis. O objetivo deste artigo é identificar e analisar criticamente as recomendações para o processo de projeto de edificações sustentáveis e relacioná-las com a estrutura de empresas de projeto. O método utilizado é a pesquisa bibliográfica, que permitiu selecionar recomendações provenientes de guias disponíveis para os profissionais da área de Arquitetura, Engenharia e Construção (AEC). O modelo de gestão proposto por Oliveira (2005), específico para pequenas empresas de projeto de edificações, foi escolhido para identificação de seus processos gerenciais. As recomendações mais frequentes nos guias se referem aos requisitos do cliente; escopo dos agentes envolvidos; papéis e responsabilidades; objetivos ambientais do empreendimento; estratégias energéticas; simulação energética; análise do projeto sustentável em relação aos requisitos do cliente, aos objetivos ambientais e programa do empreendimento; comissionamento. Essas recomendações se relacionam mais diretamente com os processos de gestão comercial e marketing, planejamento estratégico, gestão de pessoas, planejamento e controle do processo de projeto, avaliação de desempenho e serviços agregados ao projeto.
\end{abstract}

Palavras-chave: Sustentabilidade ambiental, Guias, Gestão de empresas, Projeto de edificações.

\begin{abstract}
The environmental sustainability of buildings has become a growing market demand. Design firms shall have an internal organization that enables a favorable environment for development of sustainable building designs. Our aim is to identify and to critically analyze relevant published recommendations for the design process of sustainable buildings and relate them to the structure of design firms. Bibliographical research allowed screening of recommendations available in guides for Architecture, Engineering and Construction (AEC) professionals. Oliveira (2005) management model, specific for small building design firms, was chosen for identifying their processes. The most frequent recommendations in the guides refer to client requirements; scope of the agents involved; roles and responsibilities; environmental objectives of the project; energy strategies; energy simulation; analysis of sustainable design in relation to client requirements, environmental objectives and project program; and commissioning. These recommendations relate more directly to processes of business management and marketing, strategic planning, people management, planning and control of the design process, performance evaluation and services aggregated to the design.
\end{abstract}

Keywords: Environmental sustainability, Guides, Design firms management. 


\section{INTRODUÇÃO}

A sustentabilidade ambiental de edificações tem sido uma demanda de mercado para as empresas de projeto. Assim, as empresas devem ter uma organização interna que permita gerar um ambiente mais favorável para o desenvolvimento de projetos de edificações sustentáveis.

Para Salgado, Chatelet e Fernandez (2012), mudanças na organização e gestão do processo de projeto são necessárias a fim de atender aos requisitos de desempenho ambiental da edificação, e a sua melhoria depende do estabelecimento de um sistema de gestão que auxilie os profissionais a lidarem com esses requisitos. Segundo os mesmos autores, as condicionantes da produção de edificações que considerem os princípios da qualidade ambiental podem ser divididas em técnicas e organizacionais. As técnicas se relacionam à qualidade ambiental do produto edifício em todo o seu ciclo de vida, traduzida pelas soluções de projeto. Já as organizacionais se relacionam às práticas adotadas no dia a dia das empresas, que precisam ser analisadas e adaptadas, para que os profissionais possam atender positivamente às demandas do projeto integrado fundamental para o alcance de metas de construção sustentável.

Entende-se que as práticas mencionadas devem ser apoiadas pela gestão da empresa de projeto, devido à relação com seus processos: planejamento estratégico, pela definição do foco em edificações sustentáveis; gestão de pessoas, pela capacitação; gestão comercial, pela relação com o cliente que demanda esse tipo de edificação, contratação; entre outros.

O objetivo deste artigo é identificar e analisar criticamente as recomendações para o processo de projeto de edificações sustentáveis e relacioná-las com a estrutura de empresas de projeto. Essas recomendações são provenientes de guias disponíveis para os profissionais da área de AEC (Arquitetura, Engenharia e Construção).

\section{METODOLOGIA DE PESQUISA}

A abordagem metodológica adotada na pesquisa está representada pela Figura 1.

\section{Figura 1 - Metodologia de pesquisa}

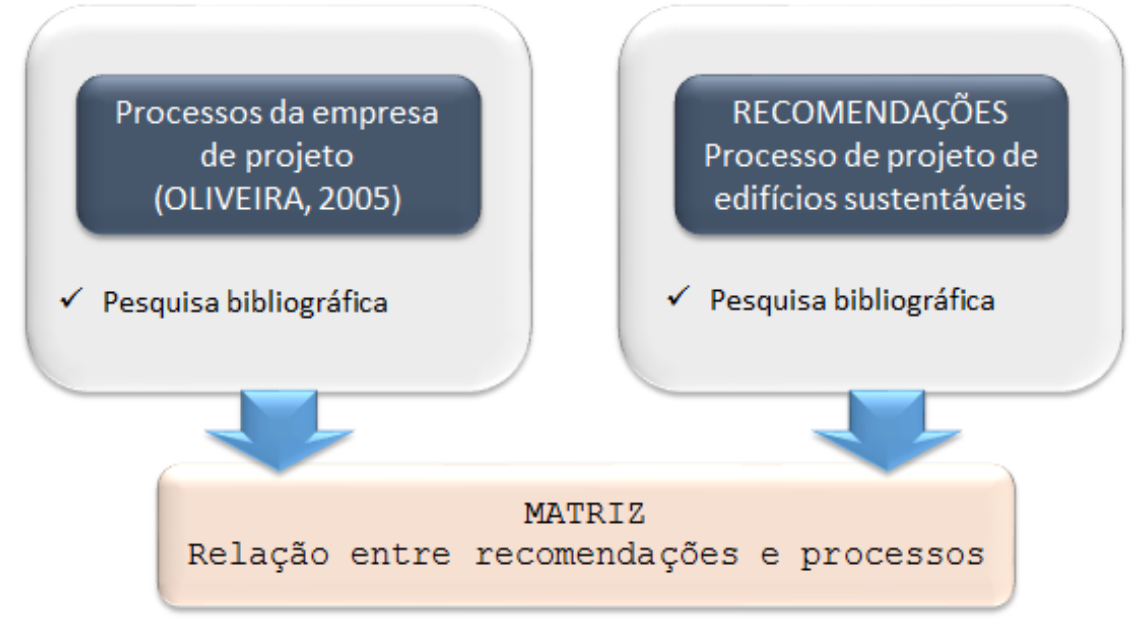

O modelo de gestão proposto por Oliveira (2005) foi escolhido para identificação dos processos por se tratar de um modelo específico para pequenas empresas de projeto de edificações. Ele é composto por nove módulos: planejamento estratégico; estrutura 
organizacional; gestão de custos; gestão de recursos humanos; gestão comercial e marketing; sistema de informação; planejamento e controle do processo de projeto; serviços agregados ao projeto e avaliação de desempenho. O Quadro 1 detalha os objetivos dos módulos de gestão no contexto da implementação do modelo em empresas de projeto.

\section{Quadro 1 - Descrição dos módulos de gestão}

\begin{tabular}{|c|c|}
\hline $\begin{array}{l}\text { Módulos de } \\
\text { gestão }\end{array}$ & Objetivos no contexto da implementação do modelo \\
\hline $\begin{array}{l}\text { Estrutura } \\
\text { organizacional }\end{array}$ & $\begin{array}{l}\text { Deve-se analisar como a estrutura da empresa permite a execução de suas } \\
\text { estratégias e a realização do seu trabalho. Além disso, deve-se considerar } \\
\text { como a estrutura se harmoniza com os indivíduos que ali trabalham e qual é } \\
\text { o impacto sobre as suas atividades. }\end{array}$ \\
\hline $\begin{array}{l}\text { Planejamento } \\
\text { estratégico }\end{array}$ & $\begin{array}{l}\text { Permite conhecer e melhor utilizar os pontos fortes da empresa; conhecer, } \\
\text { eliminar ou adequar os seus pontos fracos; conhecer e aproveitar as } \\
\text { oportunidades externas, assim como evitar as ameaças; criar uma agenda } \\
\text { para objetivos e metas da empresa. }\end{array}$ \\
\hline $\begin{array}{l}\text { Planejamento e } \\
\text { controle do } \\
\text { processo de } \\
\text { projeto }\end{array}$ & $\begin{array}{l}\text { A elaboração de instrumentos para planejamento e controle do processo de } \\
\text { projeto traz consideráveis benefícios ao processo de avaliação final do } \\
\text { projeto, tanto em relação aos aspectos técnicos quanto com relação aos } \\
\text { aspectos de gestão. Os dados advindos destes instrumentos possibilitam o } \\
\text { estabelecimento de diretrizes para aprimoramento dos novos projetos, por } \\
\text { meio da comparação entre as atividades previstas e as realmente realizadas. }\end{array}$ \\
\hline $\begin{array}{l}\text { Gestão } \\
\text { financeira }\end{array}$ & $\begin{array}{l}\text { Instrumentos simplificados para organização e controle das receitas, dos } \\
\text { custos fixos e dos custos diretos da pequena empresa de projetos de } \\
\text { edificações devem ser desenvolvidos. }\end{array}$ \\
\hline $\begin{array}{l}\text { Gestão comercial } \\
\text { e marketing }\end{array}$ & $\begin{array}{l}\text { Estratégias e ferramentas de marketing devem ser definidas com o objetivo } \\
\text { de fazer com que o cliente perceba que o serviço "projeto" é parte } \\
\text { indissociável do produto edifício, de modo a criar a sensação de necessidade } \\
\text { desse serviço. Além disso, um método para precificação dos projetos deve } \\
\text { ser estabelecido e as propostas técnico-comerciais devem ser elaboradas. }\end{array}$ \\
\hline $\begin{array}{l}\text { Sistema de } \\
\text { informação }\end{array}$ & $\begin{array}{l}\text { Mecanismos simples e consistentes para emissão, recebimento e } \\
\text { armazenagem das informações necessárias para o processo de projeto e para } \\
\text { a gestão da empresa de projeto devem ser criados, de modo a facilitar a } \\
\text { disponibilidade e a quantidade da informação no momento certo. }\end{array}$ \\
\hline $\begin{array}{l}\text { Gestão de } \\
\text { pessoas }\end{array}$ & $\begin{array}{l}\text { Procedimentos simples e básicos para a contratação de colaboradores, } \\
\text { educação continuada e treinamento devem ser propostos, bem como para a } \\
\text { organização das terceirizações, com enfoque para o aperfeiçoamento } \\
\text { tecnológico dos profissionais, melhoria do clima organizacional e garantia } \\
\text { de melhor qualidade dos projetos realizados pela empresa. }\end{array}$ \\
\hline $\begin{array}{l}\text { Serviços } \\
\text { agregados ao } \\
\text { projeto }\end{array}$ & $\begin{array}{l}\text { Práticas devem ser estabelecidas com o objetivo de criar uma linha direta de } \\
\text { comunicação com o cliente e usuários do projeto (contratante, obra e usuário } \\
\text { da edificação), de modo a aperfeiçoar continuamente o processo de projeto. }\end{array}$ \\
\hline $\begin{array}{l}\text { Avaliação de } \\
\text { desempenho }\end{array}$ & $\begin{array}{l}\text { Uma sistemática para avaliação do desempenho dos projetos desenvolvidos } \\
\text { pela empresa e avaliação do desempenho do seu sistema de gestão deve ser } \\
\text { proposta. }\end{array}$ \\
\hline
\end{tabular}

Fonte: OLIVEIRA (2005) 
Os guias foram selecionados por conter recomendações para o processo de projeto de edificações sustentáveis.

\section{A ESTRUTURA DA EMPRESA DE PROJETO E O PROCESSO DE PROJETO DE EDIFICAÇÕES SUSTENTÁVEIS}

\subsection{A empresa de projeto de edificações}

De acordo com Emmitt (2007), empresas de projeto bem sucedidas estão comprometidas em satisfazer seus clientes por meio de um bom projeto, expertise técnica, entregas dentro do programa e do orçamento; possuem objetivos de negócio claros por meio do equilíbrio entre projeto, tecnologia e gestão.

Grande parte das empresas de projeto possui uma série de deficiências em suas práticas de gestão. Em seu estudo, Souza (2009) identificou, dentre outras, as seguintes: a prática do planejamento estratégico não sistemática; ausência de fluxos de trabalho estabelecidos para os diversos processos técnicos e administrativos; desconhecimento dos métodos para a gestão financeira; funções, cargos e salários não organizados; negligência nas análises necessárias para a elaboração das propostas técnico-comerciais; falta de sistematização quanto à entrega dos projetos, visitas à obra durante a execução e avaliação pós-ocupação; ausência de indicadores para o acompanhamento do processo de projeto, nem das rotinas gerenciais da empresa como um todo na maior parte das empresas; desconhecem o fluxo de informações referentes aos diversos processos da empresa (técnico e administrativos).

Segundo Melhado (2012), "em seu "mundo único", os projetistas muitas vezes se mostram fortemente reativos às necessidades de melhoria da gestão; até certo ponto, mas não abertamente, esses profissionais questionam a real necessidade de se fazer gestão, mesmo se essa necessidade é perceptível na sua própria prática diária. Outro perfil típico do profissional de projeto pode ser denominado gestor "autodidata", representado pela adoção de métodos por vezes ineficientes e controles muito burocráticos".

Li et al. (2014) exploraram a capacidade e os recursos necessários de empresas de projeto para trabalhar com empreendimentos que buscam certificação ambiental em Cingapura. Em sua revisão bibliográfica, os autores levantaram os seguintes recursos organizacionais necessários a este tipo de empresas: capacidade financeira, competência tecnológica, experiência e conhecimento, recursos humanos, imagem da empresa, capacidade de inovação, estrutura organizacional e cultura organizacional. Por meio de uma survey e estudos de caso, os autores verificaram que os três recursos mais críticos para atuar em empreendimentos com metas ambientais são: experiência e conhecimento em green building, cultura organizacional e capacidade de inovação.

Recursos organizacionais são necessários para que a empresa participe da produção de edificações com metas ambientais, mas como relacionar a sua estrutura com projetos sustentáveis? O Quadro 2 apresenta essa relação. 


\section{Quadro 2 - Os processos da empresa de projeto e fatores relevantes em projeto sustentável}

\begin{tabular}{|c|c|}
\hline $\begin{array}{l}\text { Módulos de } \\
\text { gestão }\end{array}$ & Fatores relevantes - projeto sustentável \\
\hline $\begin{array}{l}\text { Estrutura } \\
\text { organizacional }\end{array}$ & $\begin{array}{l}\text { - Estrutura da empresa x execução das estratégias em relação a projetos } \\
\text { sustentáveis } \\
\text { - Estrutura da empresa x realização do trabalho }\end{array}$ \\
\hline $\begin{array}{l}\text { Planejamento } \\
\text { estratégico }\end{array}$ & $\begin{array}{l}\text { - Posicionamento estratégico da empresa no mercado de projetos sustentáveis } \\
\text { - Identificação dos pontos fortes, fracos, das ameaças e oportunidades em } \\
\text { relação a projetos sustentáveis }\end{array}$ \\
\hline $\begin{array}{l}\text { Planejamento e } \\
\text { controle do } \\
\text { processo de } \\
\text { projeto }\end{array}$ & $\begin{array}{l}\text { - Mapeamento do processo de projeto, incluindo novas atividades (definição } \\
\text { de objetivos ambientais, pesquisa de materiais e componentes, simulação } \\
\text { energética, comissionamento, documentação de certificação etc.), novos } \\
\text { agentes (consultores e especialistas) e novas ferramentas (ferramenta de } \\
\text { simulação, check-lists de certificação etc.) } \\
\text { - Inclusão de requisitos ambientais } \\
\text { - Levantamento de horas de trabalho dispendidas }\end{array}$ \\
\hline $\begin{array}{l}\text { Gestão } \\
\text { financeira }\end{array}$ & $\begin{array}{l}\text { - Investimentos em capacitação e tecnologia } \\
\text { - } \text { Levantamento de custos do projeto sustentável (horas de trabalho, } \\
\text { - Precificaçãão do projeto sustentável }\end{array}$ \\
\hline $\begin{array}{l}\text { Gestão } \\
\text { comercial e } \\
\text { marketing }\end{array}$ & $\begin{array}{l}\text { - Propostas técnico-comerciais que permitam o atendimento aos objetivos } \\
\text { ambientais } \\
\text { - Modelos contratuais (estimular o processo de projeto integrado) } \\
\text { - } \text { Elementos contratuais (escopo do projeto sustentável) } \\
\text { - } \text { consegue entregar o que está sendo requisitado?) } \\
\text { - Relação com o cliente contratante }\end{array}$ \\
\hline $\begin{array}{l}\text { Sistema de } \\
\text { informação }\end{array}$ & $\begin{array}{l}\text { - Objetivos ambientais } \\
\text { - Requisitos ambientais } \\
\text { - Formalização das informações } \\
\text { - Comunicação interna e com os agentes externos, equipe de projeto }\end{array}$ \\
\hline $\begin{array}{l}\text { Gestão de } \\
\text { pessoas }\end{array}$ & $\begin{array}{l}\text { - } \text { Capacitação } \\
\text { - } \quad \text { Perfil profissional } \\
\text { - } \text { Competências adequadas ao projeto sustentável } \\
\text { - } \quad \text { Matriz de responsabilidades } \\
\text { - } \text { Remuneração adequada }\end{array}$ \\
\hline $\begin{array}{l}\text { Serviços } \\
\text { agregados ao } \\
\text { projeto }\end{array}$ & $\begin{array}{l}\text { - Sistematização quanto à entrega do projeto sustentável } \\
\text { - Acompanhamento da obra (visitas) para manutenção do desempenho } \\
\text { ambiental projetado } \\
\text { - Avaliação Pós-Ocupação }\end{array}$ \\
\hline $\begin{array}{l}\text { Avaliação de } \\
\text { desempenho }\end{array}$ & $\begin{array}{l}\text { - Análise projeto sustentável x requisitos do cliente } \\
\text { - Análise projeto sustentável x objetivos ambientais } \\
\text { - Análise projeto sustentável x programa do empreendimento } \\
\text { - Criação e acompanhamento de indicadores }\end{array}$ \\
\hline
\end{tabular}

Fonte: Os autores 


\subsection{Análise e discussão - A relação entre as recomendações para o processo de projeto de edificações sustentáveis e a estrutura da empresa de projeto}

Os guias selecionados para análise estão descritos no Quadro 3.

\section{Quadro 3 - Guias selecionados para análise}

\begin{tabular}{|c|c|c|}
\hline Fonte & Título & Ano/ Paí \\
\hline AIA [1] & $\begin{array}{l}\text { Document D503 }{ }^{\mathrm{TM}}-2011 \text { - Guide for Sustainable Projects, } \\
\text { including Agreement Amendments and Supplementary Conditions }\end{array}$ & $\begin{array}{l}2011, \\
\text { EUA }\end{array}$ \\
\hline \multicolumn{3}{|c|}{$\begin{array}{l}\text { Identifica e discute pontos chaves relacionados aos novos papéis, responsabilidades, riscos e } \\
\text { oportunidades para os arquitetos e empreendedores, em função do projeto e da construção } \\
\text { sustentável. Auxilia no entendimento das considerações contratuais em relação ao projeto e à } \\
\text { construção sustentável. }\end{array}$} \\
\hline AIA [2] & $\begin{array}{l}\text { An Architect's Guide to Integrating Energy Modeling in the Design } \\
\text { Process }\end{array}$ & $\begin{array}{l}2012, \\
\text { EUA }\end{array}$ \\
\hline
\end{tabular}

Contribui para o entendimento de que a modelagem energética está relacionada ao trabalho do arquiteto. O guia é uma referência que motiva o envolvimento do arquiteto nas discussões sobre energia, enfatiza a responsabilidade deste agente.

\begin{tabular}{l|l|l}
\hline AsBEA & Guia sustentabilidade na arquitetura: diretrizes de escopo para & 2012,
\end{tabular}
projetistas e contratantes

Estabelece escopo e procedimentos para o desenvolvimento de projetos com enfoque em sustentabilidade.

\begin{tabular}{|l|l|r}
\hline \multirow{2}{*}{ ASHRAE } & $\begin{array}{l}\text { ASHRAE GreenGuide - The Design, Construction, and Operation } \\
\text { of Sustainable Buildings }\end{array}$ & $\begin{array}{r}2006, \\
\text { EUA }\end{array}$
\end{tabular}

Referência principalmente para projetistas de sistemas de HVAC\&R (Heating, Ventilation, Air

Conditioning \& Refrigeration), trata de projeto de alto desempenho e processo de projeto da perspectiva de sistemas.

\begin{tabular}{l|l} 
BSRIA & A Design Framework for Building Services
\end{tabular}

2012, UK

Apresenta uma estrutura para alocar as atividades de projeto, em conexão com o empreendimento (inclui as questões de sustentabilidade ambiental). $\mathrm{O}$ guia foi revisado para alocar as atividades relacionadas ao BIM.

\begin{tabular}{|l|l|l|}
\hline BRECSU & $\begin{array}{l}\text { Good Practice Guide 287 - The design team's guide to } \\
\text { environmentally smart buildings - energy-efficient options for new } \\
\text { and refurbished offices }\end{array}$ & 2000, UK \\
\hline
\end{tabular}

Organizado de acordo com o RIBA Plan of Work, apresenta as ações chaves a serem realizadas em cada fase de projeto para garantir a eficiência energética de edificações comerciais.

\begin{tabular}{|l|l|l|}
\hline CIBSE & Energy efficiency in buildings & 2004, UK \\
\hline
\end{tabular}

Aborda as oportunidades para se alcançar a eficiência energética da edificação. Destaca a forte interação entre a envoltória da edificação, os sistemas de aquecimento e refrigeração, iluminação etc.

\begin{tabular}{l|l}
\hline CIC & The CIC Scope Of Services Handbook
\end{tabular} 2007, UK

Compreende um escopo detalhado e integrado de serviços para a produção de edificações. Define as fases do empreendimento e as atividades a serem realizadas pelos agentes envolvidos.

\begin{tabular}{|c|c|c|}
\hline RIBA [1] & Green Overlay to the RIBA Outline Plan of Work & 2011, UK \\
\hline \multicolumn{3}{|c|}{ Trata da inserção da sustentabilidade ambiental no processo de projeto de edificações. } \\
\hline RIBA [2] & RIBA Plan of Work 2013 & 2013, UK \\
\hline
\end{tabular}

Fonte: Os autores (Org.) 
O Quadro 4 apresenta as recomendações encontradas nos guias, separadas em três categorias (planejamento do empreendimento, desenvolvimento do projeto e pósprojeto), além da relação entre essas recomendações e a estrutura da empresa, com base no modelo de Oliveira (2005). É importante destacar que os processos são interrelacionados e têm alguma relação direta ou indireta com as recomendações. O Quadro 2 evidencia aqueles com influência mais direta.

As recomendações mais frequentemente encontradas nos guias se referem aos requisitos do cliente; escopo dos agentes envolvidos; papéis e responsabilidades; objetivos ambientais do empreendimento; estratégias energéticas; simulação energética; análise do projeto sustentável em relação aos requisitos do cliente, aos objetivos ambientais e programa do empreendimento; comissionamento.

O guia do AIA [1] evidencia as responsabilidades do arquiteto referentes à sustentabilidade ambiental no projeto, a importância do escopo de projeto, esclarecendo os serviços básicos e essenciais. Os guias da ASHRAE e BRECSU, que tratam de eficiência energética, mencionam um meio de promover o envolvimento da equipe de projeto: a charrete de projeto. O guia da AsBEA tem foco no edifício, em determinar o que seria um edifício sustentável e o que deveria ser feito para produzir um.

Porém, é fundamental aquilo que nenhum dos guias mostra: como a empresa de projeto deveria se posicionar frente às recomendações para o projeto sustentável? Se a empresa deseja alcançar esse resultado (projeto sustentável), é necessário identificar os meios para se chegar a esse fim, que estão presentes na gestão, para atender às recomendações. Essas recomendações se relacionam mais diretamente com os processos de gestão comercial e marketing, planejamento estratégico, gestão de pessoas, planejamento e controle do processo de projeto, avaliação de desempenho e serviços agregados ao projeto. O SI (Sistema de informações) permeia todos os processos, com seus mecanismos para emissão, recebimento e armazenagem das informações necessárias ao processo de projeto e à gestão da empresa.

Por exemplo, o planejamento estratégico deve se articular com uma gestão comercial estruturada para melhor entendimento dos requisitos do cliente que valoriza a sustentabilidade ambiental como requisito de projeto. Igualmente, no que diz respeito à gestão de recursos humanos, será dada prioridade à capacitação técnica da equipe em soluções sustentáveis. Dado esse foco, portanto, a empresa deve contemplar a temática ambiental em todas as suas ações de gestão.

No caso das simulações de desempenho ambiental, a empresa insere a simulação em seu escopo de projeto, adquire licenças e contrata treinamentos para uso de softwares apropriados, tomando essa responsabilidade para sua equipe e organizando seu sistema de informação segundo a documentação exigida por uma certificação específica; ou define como será a interação com o responsável pela realização dessa atividade, e como esse trabalho será inserido no projeto, quando se tratar de um consultor. Tomadas as decisões estratégicas, recursos humanos, financeiros e tecnológicos devem ser mobilizados. Diante disso, fica claro que a empresa deve tomar uma posição proativa diante da realidade que é a solicitação de um projeto sustentável.

\section{CONSIDERAÇÕES FINAIS}

Entende-se que a empresa de projeto envolvida na produção de edificações com metas agressivas de sustentabilidade ambiental deve dispor de um ambiente favorável para o desenvolvimento de projetos sustentáveis. 
Quadro 4 - Relação entre as recomendações para o processo de projeto de edificações sustentáveis e a estrutura da empresa de projeto

\begin{tabular}{|c|c|c|c|c|c|c|c|c|c|c|c|c|}
\hline \multicolumn{2}{|r|}{ RECOMENDAÇÕES } & $\begin{array}{c}\text { AIA } \\
{[1]}\end{array}$ & $\begin{array}{c}\text { AIA } \\
{[2]}\end{array}$ & AsBEA & ASHRAE & BSRIA & BRECSU & CIBSE & CIC & $\begin{array}{c}\text { RIBA } \\
{[1]}\end{array}$ & $\begin{array}{c}\text { RIBA } \\
{[2]}\end{array}$ & ESTRUTURA DA EMPRESA \\
\hline \multirow{12}{*}{ 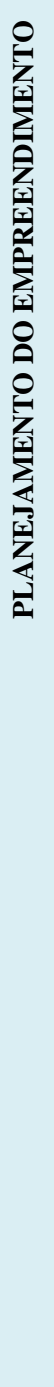 } & Discutir e entender os requisitos do cliente & $\mathrm{X}$ & $\mathrm{X}$ & $\mathrm{X}$ & $\mathrm{X}$ & $\mathrm{X}$ & $\mathrm{X}$ & $X$ & $\mathrm{X}$ & $X$ & $X$ & Gestão comercial e marketing \\
\hline & $\begin{array}{l}\text { Realizar um workshop com a equipe de } \\
\text { projeto sobre os requisitos, meios para } \\
\text { atendê-los, critérios e como medi-los }\end{array}$ & $X$ & & & $X$ & & & & & & & $\begin{array}{l}\text { Gestão comercial e marketing } \\
\text { Estrutura organizacional }\end{array}$ \\
\hline & $\begin{array}{l}\text { Estabelecer o escopo dos agentes envolvidos } \\
\text { (serviços básicos e adicionais, novos agentes) }\end{array}$ & $\mathrm{X}$ & $\mathrm{X}$ & $\mathrm{X}$ & $X$ & $X$ & & $\mathrm{X}$ & $X$ & $\mathrm{X}$ & $X$ & $\begin{array}{l}\text { Gestão comercial e marketing } \\
\text { Planejamento estratégico }\end{array}$ \\
\hline & $\begin{array}{l}\text { Se for o caso, estabelecer o escopo dos } \\
\text { serviços relacionados à certificação ambiental }\end{array}$ & $\mathrm{X}$ & & & & & & & & & & $\begin{array}{l}\text { Gestão comercial e marketing } \\
\text { Planejamento estratégico }\end{array}$ \\
\hline & $\begin{array}{l}\text { Definir e documentar os papéis e as } \\
\text { responsabilidades dos agentes envolvidos }\end{array}$ & $\mathrm{X}$ & $\mathrm{X}$ & $\mathrm{X}$ & $\mathrm{X}$ & $\mathrm{X}$ & & $\mathrm{X}$ & $\mathrm{X}$ & $\mathrm{X}$ & $\mathrm{X}$ & $\begin{array}{l}\text { Gestão comercial e marketing } \\
\text { Planejamento estratégico } \\
\text { Gestão de pessoas }\end{array}$ \\
\hline & $\begin{array}{l}\text { Inserir novos papéis, responsabilidades, } \\
\text { riscos e oportunidades em contrato }\end{array}$ & $\mathrm{X}$ & & $\mathrm{X}$ & & $\mathrm{X}$ & & $X$ & $\mathrm{X}$ & & $\mathrm{X}$ & $\begin{array}{l}\text { Gestão comercial e marketing } \\
\text { Planejamento estratégico }\end{array}$ \\
\hline & $\begin{array}{l}\text { Definir os objetivos ambientais do } \\
\text { empreendimento }\end{array}$ & $\mathrm{X}$ & & $\mathrm{X}$ & $X$ & $\mathrm{X}$ & $\mathrm{X}$ & $X$ & $\mathrm{X}$ & $\mathrm{X}$ & $\mathrm{X}$ & $\begin{array}{l}\text { Planejamento e controle do processo } \\
\text { de projeto }\end{array}$ \\
\hline & $\begin{array}{l}\text { Definir as estratégias energéticas do } \\
\text { empreendimento }\end{array}$ & & $X$ & & $X$ & $X$ & $X$ & $X$ & & $\mathrm{X}$ & $X$ & Gestão comercial e marketing \\
\hline & $\begin{array}{l}\text { Desenvolver um plano de sustentabilidade } \\
\text { (estabelecer os parâmetros de desempenho e } \\
\text { as análises projeto x desempenho) }\end{array}$ & $\mathrm{X}$ & & & & $\mathrm{X}$ & & & & & & $\begin{array}{l}\text { Planejamento e controle do processo } \\
\text { de projeto } \\
\text { Planejamento estratégico }\end{array}$ \\
\hline & $\begin{array}{l}\text { Desenvolver um plano de trabalho para } \\
\text { modelagem energética }\end{array}$ & & $\mathrm{X}$ & & & & & & & & & $\begin{array}{l}\text { Planejamento e controle do processo } \\
\text { de projeto } \\
\text { Planejamento estratégico }\end{array}$ \\
\hline & $\begin{array}{l}\text { Identificar a necessidade de novas } \\
\text { ferramentas no processo de projeto }\end{array}$ & & $\mathrm{X}$ & $\mathrm{X}$ & $\mathrm{X}$ & $\mathrm{X}$ & & & & & & $\begin{array}{l}\text { Planejamento e controle do processo } \\
\text { de projeto } \\
\text { Planejamento estratégico } \\
\text { Gestão financeira }\end{array}$ \\
\hline & $\begin{array}{l}\text { Identificar as restrições do empreendimento/ } \\
\text { projeto }\end{array}$ & & $\mathrm{X}$ & $\mathrm{X}$ & & $\mathrm{X}$ & $\mathrm{X}$ & $X$ & $\mathrm{X}$ & $\mathrm{X}$ & & $\begin{array}{l}\text { Planejamento e controle do processo } \\
\text { de projeto }\end{array}$ \\
\hline
\end{tabular}




\begin{tabular}{|c|c|c|c|c|c|c|c|c|c|c|c|c|}
\hline \multicolumn{2}{|r|}{ RECOMENDAÇÕES } & \multirow{2}{*}{$\begin{array}{c}\text { AIA } \\
{[1]} \\
X\end{array}$} & \multirow[t]{2}{*}{$\begin{array}{l}\text { AIA } \\
{[2]}\end{array}$} & \multirow{2}{*}{$\begin{array}{c}\text { AsBEA } \\
X\end{array}$} & \multirow[t]{2}{*}{ ASHRAE } & \multirow{2}{*}{$\begin{array}{c}\text { BSRIA } \\
\mathrm{X}\end{array}$} & \multirow[t]{2}{*}{ BRECSU } & \multirow{2}{*}{$\begin{array}{c}\text { CIBSE } \\
\mathrm{X}\end{array}$} & \multirow{2}{*}{ CIC } & \multirow{2}{*}{$\begin{array}{c}\text { RIBA } \\
{[1]} \\
X\end{array}$} & \multirow[t]{2}{*}{$\begin{array}{c}\text { RIBA } \\
{[2]}\end{array}$} & \multirow{2}{*}{$\begin{array}{l}\text { ESTRUTURA DA EMPRESA } \\
\begin{array}{l}\text { Planejamento e controle do processo } \\
\text { de projeto }\end{array}\end{array}$} \\
\hline 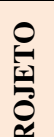 & $\begin{array}{l}\text { Pesquisar e selecionar materiais e } \\
\text { componentes que atendam aos objetivos } \\
\text { ambientais do empreendimento }\end{array}$ & & & & & & & & & & & \\
\hline \multirow{6}{*}{ 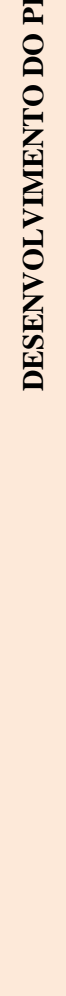 } & $\begin{array}{l}\text { Realizar simulações ambientais que auxiliem } \\
\text { na tomada de decisão }\end{array}$ & & $\mathrm{X}$ & $\mathrm{X}$ & $\mathrm{X}$ & $\mathrm{X}$ & & & & & $\mathrm{X}$ & $\begin{array}{l}\text { Planejamento e controle do processo } \\
\text { de projeto }\end{array}$ \\
\hline & $\begin{array}{l}\text { Integrar a simulação energética ao processo } \\
\text { de projeto }\end{array}$ & & $\mathrm{X}$ & & $\mathrm{X}$ & $\mathrm{X}$ & & $\mathrm{X}$ & & & & $\begin{array}{l}\text { Planejamento e controle do processo } \\
\text { de projeto } \\
\text { Planejamento estratégico }\end{array}$ \\
\hline & Realizar simulação energética & & $\mathrm{X}$ & $\mathrm{X}$ & $\mathrm{X}$ & $\mathrm{X}$ & $\mathrm{X}$ & $\mathrm{X}$ & & & & $\begin{array}{l}\text { Planejamento e controle do processo } \\
\text { de projeto } \\
\text { Gestão de pessoas }\end{array}$ \\
\hline & $\begin{array}{l}\text { Facilitar a realização de simulações por meio } \\
\text { do BIM }\end{array}$ & & & & $\mathrm{X}$ & $\mathrm{X}$ & & & & & & $\begin{array}{l}\text { Planejamento e controle do processo } \\
\text { de projeto } \\
\text { Planejamento estratégico }\end{array}$ \\
\hline & $\begin{array}{l}\text { Realizar análises (passa pela definição de } \\
\text { indicadores) } \\
\text { Análise projeto sustentável x requisitos do } \\
\text { cliente } \\
\text { Análise projeto sustentável x objetivos } \\
\text { ambientais } \\
\text { Análise projeto sustentável x programa do } \\
\text { empreendimento }\end{array}$ & $\mathrm{X}$ & $\mathrm{X}$ & $\mathrm{X}$ & $\mathrm{X}$ & $\mathrm{X}$ & $\mathrm{X}$ & $\mathrm{X}$ & & $\mathrm{X}$ & & $\begin{array}{l}\text { Planejamento e controle do processo } \\
\text { de projeto } \\
\text { Gestão comercial e marketing } \\
\text { Avaliação de desempenho }\end{array}$ \\
\hline & $\begin{array}{l}\text { Identificar e planejar os serviços de } \\
\text { comissionamento (plano, critérios de } \\
\text { desempenho dos sistemas etc.) }\end{array}$ & $\mathrm{X}$ & $\mathrm{X}$ & $\mathrm{X}$ & $\mathrm{X}$ & $\mathrm{X}$ & $\mathrm{X}$ & $\mathrm{X}$ & & $\mathrm{X}$ & $\mathrm{X}$ & $\begin{array}{l}\text { Planejamento e controle do processo } \\
\text { de projeto } \\
\text { Serviços agregados ao projeto }\end{array}$ \\
\hline \multirow{2}{*}{ 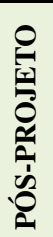 } & Realizar os serviços de comissionamento & $\mathrm{X}$ & $\mathrm{X}$ & $\mathrm{X}$ & $\mathrm{X}$ & $\mathrm{X}$ & $\mathrm{X}$ & $\mathrm{X}$ & & $\mathrm{X}$ & $\mathrm{X}$ & $\begin{array}{l}\text { Serviços agregados ao projeto } \\
\text { Gestão de pessoas }\end{array}$ \\
\hline & $\begin{array}{l}\text { Esclarecer as responsabilidades do } \\
\text { proprietário quanto à operação e manutenção } \\
\text { da edificação }\end{array}$ & $\mathrm{X}$ & & & $\mathrm{X}$ & $\mathrm{X}$ & $\mathrm{X}$ & $\mathrm{X}$ & & $\mathrm{X}$ & $\mathrm{X}$ & Gestão comercial e marketing \\
\hline
\end{tabular}

Fonte: Os autores

SI = Sistema de Informação 
A gestão da empresa de projeto tem influência em como as recomendações descritas neste artigo podem ser atendidas por meio dos seus processos internos. Muitas vezes, a sustentabilidade ambiental é entendida como uma disciplina de projeto estanque, em que o consultor é o responsável e a empresa de projeto realiza apenas o que é solicitado por ele. Nesse caso, os processos internos pouco evoluem para dar suporte ao desenvolvimento de projetos mais sustentáveis.

\section{AGRADECIMENTOS}

Os autores agradecem à Capes pela bolsa de pesquisa concedida a uma das autoras.

\section{REFERÊNCIAS}

AIA (American Institute of Architects). Document D503ТM - 2011 - Guide for Sustainable Projects, including Agreement Amendments and Supplementary Conditions. 05 set. 2011.

AIA (American Institute of Architects). An Architect's Guide to Integrating Energy Modeling in the Design Process. 2012.

AsBEA (Associação Brasileira dos Escritórios de Arquitetura). Guia sustentabilidade na arquitetura: diretrizes de escopo para projetistas e contratantes. 2012.

ASHRAE (American Society of Heating and Air-Conditioning Engineers). ASHRAE GreenGuide - The Design, Construction, and Operation of Sustainable Buildings. 2006.

BSRIA (Building Services Research and Information Association). A Design Framework for Building Services. 2012.

BRECSU (Building Research Energy Conservation Support Unit). Good Practice Guide 287 The design team's guide to environmentally smart buildings - energy-efficient options for new and refurbished offices. 2000.

CIBSE (Chartered Institution of Building Services Engineers). Energy efficiency in buildings. 2004.

CIC (Construction Industry Council). The CIC Scope Of Services Handbook. 2007.

EMMITT, S. Design Management for Architects. Oxford: Blackwell Publishing, 2007.

LI, Y. Y. et al. Exploration of critical resources and capabilities of design firms for delivering green building projects: Empirical studies in Singapore. Habitat International, v.41, p.229235, jan. 2014.

MELHADO, S. B. Gestão de projetos complexos e as novas demandas. In: SALGADO, M. S. et al. Projetos complexos e seus impactos na cidade e na paisagem. Rio de Janeiro: UFRJ/FAU/PROARQ; ANTAC, 2012.

OLIVEIRA, O. J. Modelo de gestão para pequenas empresas de projeto de edifícios. 2005. 262 p. Tese (Doutorado em Engenharia de Construção Civil e Urbana) - Escola Politécnica, Universidade de São Paulo, São Paulo, 2005.

RIBA (Royal Institute of British Architects). Green Overlay to the RIBA Outline Plan of Work. 2011.

RIBA (Royal Institute of British Architects). RIBA Plan of Work 2013. 2013.

SALGADO, M. S.; CHATELET, A.; FERNANDEZ, P. Produção de edificações sustentáveis: desafios e alternativas. Ambiente Construído, v.12, n.4, p.81-99, out./dez. 2012.

SOUZA, F. R. Implementação de modelo de gestão para empresas de projeto. 2009. 202p. Dissertação (Mestrado em Engenharia de Construção Civil) - Escola Politécnica, Universidade de São Paulo, São Paulo, 2009. 